\title{
Mentors' Multiple Intelligences (MI) Teaching Styles and Students' Multiple Intelligences
}

\author{
Maria Lilibeth G. Castil, Ph. D. \\ Bohol Island State University, Main Campus, Tagbilaran City, Bohol, Philippines \\ mlgcastil@yahoo.com
}

\begin{abstract}
With the challenges of child-centered curriculum, the learning process must be adapted to the unique capacities and intelligences of the learners. Being the facilitators of learning process, mentors must use and design teaching styles responsive to the innate capacities and inclinations of the learners. Thus, this study explored the profile of the mentors' multiple intelligences (MI) teaching styles and students' $M I$ and its compatibility. The findings of this study intend to provide basis for the enhancement of mentors' understanding of students' differing intelligences. This is a quantitative research employing descriptive and inferential designs. There were 45 Teacher Education mentors and 559 student respondents of the five campuses of Central Visayas State College of Agriculture, Forestry and Technology now Bohol Island State University. Cluster stratified sampling was used to determine the student respondents stratified according to course and year level. Total enumeration was used for the mentor respondents. To gather data for mentors' MI teaching styles and students' MI, the survey scales and questionnaires on MI teaching methods and strategies by Armstrong (1994) and MI checklist by McKenzie (1999-2001) were modified, pilot tested and administered. The weighted mean was used to show the MI profiles, while, T-test of difference of independent means was used to show the compatibility between the mentors' MI teaching styles and students' MI. Findings show that mentors having a weighted mean of 3.41 (frequently applied) used predominantly the verbal-linguistic, mathematical-logical, interpersonal, intrapersonal, naturalistic and existential (MI) teaching styles, however, bodily-kinesthetic, musical and spatial teaching styles were seldom applied. The findings imply that though mentors used a variety of teaching styles, some styles need to be developed and infused in their teaching repertoire. Meanwhile, students generally showed wider array and higher manifestation of MI having a weighted mean 3.64 (agree) except on musical intelligence. These findings suggest that learners need more opportunities to explore, tap and develop the musical intelligence. Further, mentors' MI teaching styles and students' MI showed significant difference, except on mathematical-logical and interpersonal intelligences. The computed $t$ values were higher than the tvalue of 1.96 at 602 df at .05 level of significance, rejecting the null hypothesis. Generally, the mentors' MI teaching styles did not totally correspond to students' MI. Hence, mentors may be provided with capacity building to broaden their MI teaching styles, as well as design instructional strategies, techniques and activities that will match the learners' diverse intelligences. Learners have distinct ways of obtaining and processing information, hence, the teaching styles must be attuned to these capabilities to facilitate learning.
\end{abstract}

Keywords: Multiple Intelligences (MI), MI Teaching Styles, Students' MI, Existential Intelligence, Intrapersonal, Intelligence

\section{Introduction}

The aim of education is to ascertain effective learning and holistic development of the learners. To achieve this, educational plans reflecting the educational philosophy and 
psychology of learning are designed and implemented to improve the approaches and techniques in teaching. Recently, experts in the field generally recognize the concept of individual differences. They affirmed the uniqueness of individual learning styles and set of intelligences. Thus, teaching requires that learning content, pace, techniques and approaches must be adapted to the capacities, interest, and uniqueness of the learner. This principle is concretely illustrated in the philosophy of a child-centered curriculum.

Mentors are entrusted for the learners to develop the competencies for critical, creative, independent thinking as well as the social, personal and interpersonal skills. To ensure learning mentors must know what to teach and how to teach it in the most effective manner. The diverse intelligences could be developed through a multi-sensory and multimode approach. Likewise, students learn best when teaching approaches fit their learning style and type of intelligence [1]. With the new generation of learners who are exposed and adept to the stimulating world of information technology, innovative education is required to respond to the multiplicity of their interests. Teachers have to be ready to cater to these diverse capacities and challenges to create a dynamic learning environment.

Accentuated recently is the multiple intelligences (MI) proposed by the American psychologist Howard Gardner. He presented nine intelligences such as the linguistic which manifests a highly developed verbal skills and sensitivity to sounds, meaning, and rhythm of words; the mathematical-logical which exemplifies the ability to think conceptually and abstractly, the ability to discern logical or numerical patterns; the spatial which reveals the capacity to think in images and pictures, to visualize accurately and abstractly; the musical which expresses the ability to produce and appreciate rhythm, pitch, and timber; the body-kinesthetic which shows the ability to control one's body movements and to handle objects skillfully; the interpersonal which enables the person to turn his cognitive and affective faculties outward to other individuals; the intrapersonal which manifests for self-understanding, self-discipline, self-esteem, selfaware and in-tune with inner feelings, values, beliefs, and thinking processes; the naturalist which shows the ability to recognize and categorize plants, animals, and other objects in nature; and the existential which reveals the sensitivity and capacity to tackle deep questions about human existence, such as the meaning of life [2].

Research on individual differences has contributed teachers' understanding that people are unique; that learners will respond differently to a variety of instructional content and methods; and that mentors need to respect the individual differences among the students. To be effective in the teaching- learning process, mentors must tap and cater to the intelligences not measured in standardized I.Q. tests. Students could develop their potentials if given the opportunity to experience different activities that would enhance predominant intelligences and develop latent ones.

Thus, this study explored the profile and the matching of the mentors' MI teaching styles and students' multiple intelligences. The result of the study would bear implication to the curriculum design and programs, mentors' teaching styles and development of students' MI.

\section{Materials and Methods}

This is a quantitative research employing descriptive and inferential designs. The weighted mean was used to show the profiles of the variables, while, T-test of difference of independent means was used to show the matching of the mentors' MI teaching styles and students' multiple intelligences.

This study was conducted in the five campuses of Central Visayas State College of Agriculture Forestry and Technology in Bilar, Calape, Candijay, Clarin and Tagbilaran City, now Bohol Island State University. The respondents were the 45 mentors and 559 freshmen to junior students of the College of Teacher Education. Cluster stratified sampling was used considering the strata on course and year level. 
To determine the mentors' teaching styles, the modified scale on the Multiple Intelligences (MI) Teaching Methods and Strategies was used [3]. It contained nine areas with 15 items that correspond to Gardner's nine Multiple Intelligences (MI). The fivepoint Likert scale from "always applied" to "never applied" was used to describe the teaching styles.

The students' multiple intelligences were measured by a modified Multiple Intelligences Survey Form and Checklist for Assessing Students' MI of Wallet McKenzie (1999-2001) and MI Scales by Armstrong (1994) which correspond to Gardner's nine multiple intelligences [4,3]. Each category consisted of 10 items using the five-point Likert scale from "strongly agree" to "strongly disagree".

The Pearson-product-moment correlation coefficient and Spearman- Brown formula were used to get the reliability coefficient of internal consistency of the MI teaching styles scale at 0.83; Students' MI at 0.68.

The weighted mean were used to show the profiles of the mentors' MI teaching styles and students' MI. To obtain the matching of the MI teaching styles and students' MI, the t- test of difference of independent means was used.

\section{Results and Discussions}

\subsection{Profile of Mentors' MI Teaching Styles and Students' Multiple Intelligences}

The mentors' cognitive interaction with the students, the ways of organizing, motivating, presenting, evaluating instructions and managing classroom environment characterize the teaching styles which are crucial roles of a teacher. These teaching styles affect the dynamics of the learning process. There are numerous teaching styles but it has been theorized that styles responsive to students' needs, interests, and intelligences tend to elicit effective learning.

Figure 1 shows the mentors' MI teaching styles and students' multiple intelligences. The mentors' MI teaching styles reveal that verbal-linguistic, mathematical-logical, interpersonal and intrapersonal, naturalistic and existential teaching styles were frequently applied, while, the musical, visual-spatial and bodily-kinesthetic were sometimes applied.

On linguistic teaching style, mentors always required students to make oral presentations and frequently used lecture, discussions, explanations, reading materials and writing on understanding but sometimes used debates, interviews, compositions, storytelling, talk shows, presentations and audio tapes. This result concurred with the findings that most teachers utilized class discussion and lecture method and other activities which developed an interchange of ideas between the teacher, the learner and among the learners themselves. Teacher demonstration was used occasionally and media were rarely used due to absence of equipment [5].

The mathematical-logical teaching style was also frequently used particularly in breaking topics logically, classifying information, creating story problems and strategy games, making analogies and timelines, developing and testing hypothesis, developing thinking skills translating concepts into formulas. However, mentors sometimes used the methods on counting or measuring mathematically, making syllogisms or analogies in explaining, designing codes, describing patterns, or conducting experiments. In Gestalt theory, showing a pattern, providing a holistic view and clarifying the relationship among parts will aid the learning process. Further, Vygotsky's emphasis on scaffolding, particularly, in providing cues, explanations, and providing more examples will help the learners overcome learning difficulties [6].

Generally, mentors sometimes applied the spatial, musical, and bodily-kinesthetic teaching style. Specifically, mentors frequently used the method on presentation of models, visualization, charts, maps or graphs but rarely used the visual media may be due to the absence of equipment. With musical teaching style, they rarely required students to 
present lessons through lyrics, musical pieces, or in rhythmical patterns. Meanwhile, mentors sometimes used the bodily-kinesthetic teaching style, such as the use of handson materials, puzzles, board or floor game, choreography, role trough action. However, they frequently allowed students to move around the class, manipulate materials, express ideas through action, attend filed trips, make models, design product and make use of good physical qualities.

Traditionally, spatial capacities, body manipulation and musical abilities are considered as special assets not intelligences. Teachers may perceive these intelligences as less important, so that they moderately used it as a teaching approach. The result implies that mentors need training to tap and optimize the moderately used spatial, musical, and bodily-kinesthetic teaching styles.

Interpersonal teaching style was frequently used by teachers particularly the group work, group presentation, cooperative games, role playing, service projects, group meetings and solution of local or global problem. Only the peer tutoring was rated "sometimes". According to Gardner (1983) the interpersonal teaching style reflects the mentors' ability to discern and respond appropriately among the moods, temperaments, motivations and intentions and to act upon this knowledge. Moreover, Piagetians suggest that the interactions in the group can create the cognitive conflict and disequilibrium that lead an individual to question his understanding and try out new ideas [6]. Likewise, Vygotsky emphasized that social interaction is important in learning because higher mental functions such as reasoning, comprehension and critical thinking originate in social interactions and are internalized by the individuals. Social support and scaffolding are needed for students to move learning forward [7].

On intrapersonal teaching style, only the choice of one's own learning was rated "sometimes" which imply that mentors need to provide the students the opportunity to choose as to the method and content of the lesson or activity in the class. This is understandable since most of the lessons were already predetermined and defined in the course syllabus or curriculum. However, the freedom to determine their own project or activity will enhance the students' self-confidence, creativity and involvement. The rest of the teaching styles were rated "frequently" like the assignment of individual work; reflection of learning, experiences, philosophy, values or purposes; journal writing, personal analogy, goal setting, self-assessment of work, and conduct of project of own choice. This component reflects the mentors' self-knowledge and the ability to adapt on the basis of that knowledge.

Generally, the naturalistic teaching style was frequently used by exposing the class outdoors and learning from the natural order, requiring reports, reaction of analysis on environment concerns, brainstorming on environmental issues, and encouraging the class o use natural elements or processes. Classifying objects, plants or animals, displaying plants in class, relating information to nature, making observation on celestial things or cycles of nature were sometimes used. Only the exhibit of animals in one's class was rarely done. This finding indicates the mentors' inclination to tap nature in the teachinglearning process to enliven the learning milieu and to develop the learners' affinity to nature.

Another frequently used teaching style was the existential style. Mentors allowed students to mediate and value learning, to discuss questions about life existence, rationality and mortality, to connect lessons with history and culture, and to help the class recognize the challenges and the bright side of life. Mentor sometimes allowed students to view art works, related lessons with philosophers, stimulated class to see events after death or beliefs on spirits. This finding indicates a need to expose learners to museums, historical spots, movies or documentaries, which portray various beliefs, lifestyles or ideologies to broaden the learners' concept about life and even death phenomena.

It can be gleaned from the findings that mentors frequently used a variety of teaching styles but some teaching styles need to be infused further in the teaching repertoire. 
According to Dunkin and Biddle (1982), teachers who use an indirect style of teaching seem to be aware and to make the most of student diversity. They also tend to be more democratic and flexible. Further, the way one will be inclined to teach depends in part on the teaching styles to which one have been exposed [8]. Moreover, most theories on effective learning advocate the use of multisensory approach, involvement of more modes of learning, provision of hands-on experience, and the like. Students must also grasp the meaningfulness of the material. Learning will seemingly transpire if the presentation of the material links to one's multiple intelligences.

Mentors might have a preferred way of teaching, however, it is strongly implied in the MI theory that teaching and learning should focus on the particular intelligences of each person, thereby requiring the mentors to use broad range of teaching strategies. This implies that mentors may have used a variety of teaching styles; however, some styles need to be developed and infused in their teaching repertoire.

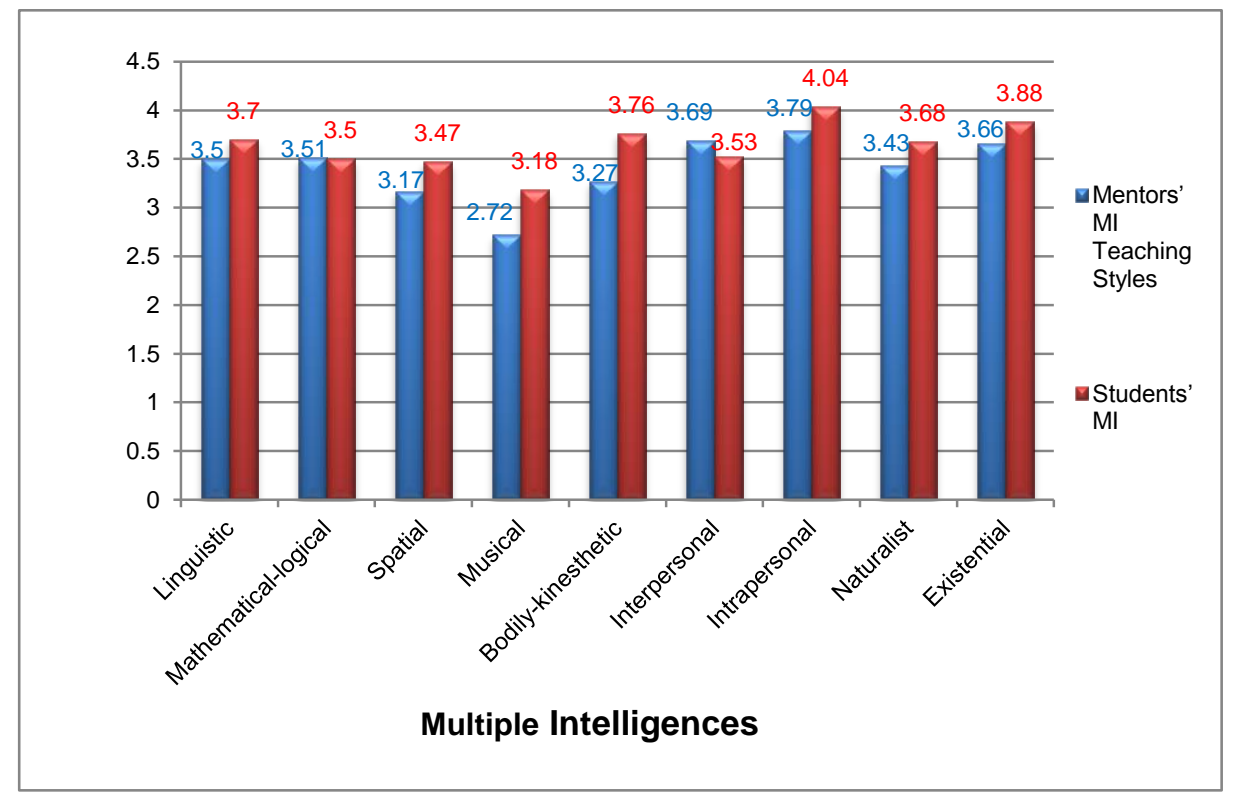

\section{Figure 1. Profile of Mentors' MI Teaching Styles and Students' Multiple Intelligences $(\mathrm{N}=604)$}

Learners vary a great deal in many aspects particularly in the aptitudes, interests, intelligences and the like. Sufficient opportunities and proper guidance may help them choose and engage in activities they and the society can profit most.

As can be seen in Table 1, students confirmed their linguistic intelligence as revealed in their capacities for English and history than math or science; reading debating, talking about ideas, playing word games, listening to explanations and interpreting diagrams and maps needed explanations. They "slightly agree" in their capacity for memorization, particularly with the audio media. This result showed succinctly the importance of the use of multiple avenues in the learning process like the complementary of visual media for audio inputs. The result conceded with the findings that students' prefer the discussionlecture method in teaching. Student felt the needs for teachers to provide them more input to fill the gap. Students also preferred fieldtrips, film-showing, and the use of hand-out, books and magazines; use of gestures, face and bodily expressions in discussions [9].

In a rapidly changing society, one cannot provide all the facts to the learners, but can teach them how to assess knowledge, evaluate information and discover things for themselves [10]. The emphasis in modern classroom is less on memorization but more on cognitive skills as thinking and reasoning. Emphasis on memorization would result to student's boredom, short-term memory an uncritical thinking. Thus, varied teaching styles 
or techniques should be used to stimulate the interest, improve the retention and develop the critical thinking of the students.

On mathematical-logical intelligence, students assessed themselves as having much capacity working on step-by-step direction, thinking first the process before a thing is done, applying cause-effect strategies, searching for patterns or logical sequence, solving brain-teasers or puzzles and thinking on abstract concepts, and starting work even if some questions were left unanswered. However, the capacity for solving problems, computing numbers in the head, learning math and science subjects were rated "slightly agree". This profile concurred with the findings in verbal-linguistic intelligence wherein students showed affinity with English and history subjects than math subjects. This implies that students may like the math and science subjects if these were taught with exhaustive verbal explanations and discussions, a step-by-step process which are familiar to the students.

They also confirmed on their spatial intelligence particularly on remembering and understanding things with the use of mental pictures, graphic organizers, charts, pictures or tables; preference on written instructions than oral inputs; watching the facial and body language to fully understand. Nonetheless, creating art, drawing, sketching, reading maps, solving jigsaw or solving 3D puzzles and geometry were slightly confirmed. The findings endorse the "law of intensity" in learning. The use of varied visual media augment the students' ability to remember things as validated by the law of sense dependence that is the more senses involved, the better the learning. This further proved the notion that the best way to learn is learning by doing. Some psychologists believe that information coded both visually and verbally is easiest to learn. Hence, explaining an idea with words and presenting it visually has proved helpful to students. A finding revealed that the use of graphs along with written text helped sixth grade students to remember more about Greece [11].

Only the musical intelligence was confirmed slightly. Students have a wide array of inclination with the exemption on musical component. A study affirmed that there was a wide variety of individual styles and usage patterns in the students' use of the multimedia instructional program which presumes that students have versatile capacities and interests [12]. On the other hand, the musical intelligence seems to need more opportunities for stimulation and development. Normally, musical repertoire is associated with leisure and diversion, never as intelligence. In this case, programs or activities maybe designed to provide them the opportunities to stimulate the interest and avenues to express the learners' musical intelligences. Moreover, a study showed that native American students perceived their musical intelligence as the least predominant intelligence, while, naturalistic and visual-spatial were perceived to be the most predominant intelligence [13].

The bodily-kinesthetic intelligence revealed to be a characteristic of the students. The result showed the value put on the non-verbal language and on learning by doing. This finding may be attributed to the principle on learning by doing as the overriding principle and practice of locale of this study as a technical and agricultural institution. On the other hand, preference on outdoor games and communication through gestures was slightly confirmed. This finding confirms the capacities on verbal expression as shown to be a strong characteristic in verbal-linguistic intelligence. However, manipulation of things and tools, production of ideas during physical activities, learning through practice and doing things were confirmed. It is implied in the result that learning and discovery are amplified when students are exposed in the actual work.

Interpersonal intelligence was shown in the concern for social issues and causes; ability to productively interact with others in learning activities, in doing projects, and engaging in extracurricular activities. Although, generally attuned with others, the respondents manifested a moderate capacity in being a team player, in defining issues from the various views of others. They moderately disliked working alone. These findings 
elicit a need to develop the concept on teamwork where the ideas of others and working together toward a common goal are the main concerns. Further, the focus on the real value of the work should be understood to facilitate teamwork instead of excessive competition in getting good grades.

Intrapersonal intelligence was manifested in examining thoughts and feelings, learning from failures or successes, affecting attitude for learning, knowing one's motives for actions, reflecting about life, expressing accurate feelings, high sense of self, fairness and justice. This finding shows the ability for self-introspection, however, the result reveals a need to strengthen one's self-esteem.

Naturalist intelligence was also confirmed through learning from and enjoying nature, engaging in camping and hiking, recognizing species by common traits, learning from ecological issues and natural sciences. These results exhibit a match of the students' capacities and fields of interest in agriculture, fishery and forestry, which are the main thrusts of the institution in this study. However, the capacity to identify different types of birds, trees or plants and the desire to study natural sciences was slightly affirmed. This result concurs with the respondents' slight agreement to memorization, which is required in remembering the nomenclature of species. The findings show that the students have the general inclination towards nature, but, the interest towards the specific aspects of the field needs further motivation.

The respondents revealed a prevailing existential intelligence particularly in defining the context of one's role; studying history, culture, religion and issues in philosophy, meditating, viewing masterpieces, discussing about life, visiting breath-taking sites, and knowing the value of things. These findings confer the importance of clarifying purposes or objectives in any activity or learning process. Cognitive theorists believe that learning is the result of the attempt to make sense of the world [14]. Nonetheless, reading ancient and modern philosophers was slightly affirmed. This result implies that the relevance of the issue or concept should be expounded to capture the interests of students in the work of philosophers.

It can be seen that learners have wide range and distinct MI or cognitive styles of obtaining and processing information, so that teaching styles and instructional strategies being attuned to these capabilities would facilitate the learning process. The stability of the learning style allows the teachers to plan and execute lessons flexibly and responsively [8]. Moreover, the stability of learning styles enables teachers to adapt instructions accordingly [15].

Further, Gardner (1983) claimed that different intelligences represent not only different content domains, but also learning modalities that reflect one's different ways of interacting with the world [2]. The findings indicated the potentials of the students which could serve as the basis in the teachers' choice in the delivery of lessons as it is central in the MI theory to focus on the learners' capacities to bring out their potentials. Hence, mentors must possess a repertoire of teaching styles to respond to the students' wide array of MI.

\subsection{Differences in the Mentors' MI Teaching Styles and Students' Multiple Intelligences}

As shown in Table 1, all MI teaching styles and students' MI except the mathematicallogical and interpersonal components showed a significant difference. These findings show that the mentors' teaching styles were not closely compatible with the students' MI. This finding may be attributed to the non-exposure of the mentors to the recently popularized MI approaches. In addition, teacher burn-out may also be a possible explanation of becoming more traditional in their teaching behavior and attitude over time. Teachers tend to conform to what is expected of them in the culture of schooling [16]. Hence, the implication to develop and broaden the mentors' teaching styles to match the students' MI. 
Table 1. Differences between the Mentors' Teaching Styles and Students' MI $(\mathrm{N}=604)$

\begin{tabular}{|c|c|c|c|c|}
\hline \multirow[t]{2}{*}{$\begin{array}{c}\text { Multiple } \\
\text { Intelligences }\end{array}$} & $\begin{array}{c}\text { Mentors' } \\
\text { Ml } \\
\text { Teaching } \\
\text { Styles } \\
(\mathrm{N}=45) \\
\end{array}$ & $\begin{array}{c}\text { Students' } \\
\mathrm{Ml} \\
(\mathrm{N}=559)\end{array}$ & \multirow{2}{*}{$\begin{array}{c}\text { Computed t } \\
\text { value at } \\
\text { tabulated } \\
\text { value } 1.96 \\
@ .05 \text { level } \\
\text { of } \\
\text { significance }\end{array}$} & \multirow[t]{2}{*}{ Decision } \\
\hline & \multicolumn{2}{|c|}{ Weighted Mean } & & \\
\hline Linguistic & 3.50 & 3.70 & $-2.08^{*}$ & Rejected \\
\hline $\begin{array}{l}\text { Mathematical- } \\
\text { logical }\end{array}$ & 3.51 & 3.50 & 0.06 & Accepted \\
\hline Spatial & 3.17 & 3.47 & $-3.21^{*}$ & Rejected \\
\hline Musical & 2.72 & 3.18 & $-4.70^{*}$ & Rejected \\
\hline $\begin{array}{l}\text { Bodily- } \\
\text { kinesthetic }\end{array}$ & 3.27 & 3.76 & $-5.40^{*}$ & Rejected \\
\hline Interpersonal & 3.69 & 3.53 & 1.69 & Accepted \\
\hline Intrapersonal & 3.79 & 4.04 & $-2.91^{*}$ & Rejected \\
\hline Naturalist & 3.43 & 3.68 & $-2.90^{*}$ & Rejected \\
\hline Existential & 3.66 & 3.88 & $-2.42^{*}$ & Rejected \\
\hline
\end{tabular}

The use of preferred intelligences in learning and instructional activities appeals to the learners [2]. Moreover, if someone enjoys what he is doing, chance is that they will be better in that position [18]. Evidence on emotional quotient testify that people who are emotionally adept know how to manage well their feelings and deal effectively with other people's feelings are at an advantage in any domain in life [19].

\section{Conclusion}

Mentors' MI teaching styles correspond marginally to the array of students' multiple intelligences. These findings suggest a need to modify, enhance and widen the variety of teaching styles to effectively meet and stimulate the students' multiple intelligences. Mentors need to view the students in a holistic manner from multiple perspectives as a developing being; intellectually, emotionally, culturally, socially and morally. They may observe and record significant information about the learners which could be used as basis in innovating and implementing teaching styles and instructional interventions responsive to students' MI.

Administrators may provide faculty members relevant trainings and workshops that will broaden their portfolio of teaching styles and authentic assessment techniques to enhance their competencies in dealing with students' multiple intelligences. Further, mentors as learning facilitators may collaborate with a team of mentors in designing MI approaches, instructional interventions and innovations, multi-sensory presentations, real life experiences or authentic activities and field exposures to adequately respond to the diversity of learners' background, needs, interests, and multiple intelligences.

\section{References}

[1] H. S. Tenedero, "Breaking the I.Q. Myth", Manila: Henyo Publishing, (1998).

[2] H. Gardner, "Reflections on MI: Myths and Messages", Boston: Allyn \& Bacon, (1998).

[3] T. Armstrong, "Multiple Intelligences in the Classroom", Alexandria, VA: Association for Supervision and Curriculum Development, (1994).

[4] W. McKenzie, "Multiple Intelligences Inventory", http://surfaquarium.com/MI/inventory.htm, (1999).

[5] A. A. Evangelio, "Teaching Styles of Science Teachers in the Network of High Schools in Region V. A Proposed in- service Training Program”, Unpublished Master's Thesis, USC, Cebu City, (1994). 
[6] A. Woolfolk, "Educational Psychology", US: Allyn and Bacon Company, (2001).

[7] P. Eggen and D. Kauchack, "Educational Psychology", New Jersey: Pearson Education, Inc., (2013).

[8] D. R. Cruickshank, D. B. Jenkins and K. K. Metcalf, "The Act of Teaching", New York: McGraw-Hill, (2003).

[9] E. M. Luminarias, "Cognitive Adequacy and Attitude of College Students towards Philippine Literature", Unpublished Master's Thesis, University of Bohol, Tagbilaran City, (2000).

[10] J. W. Astingson, "Theory of Mind Goes to School", Educational Leadership, vol. 56, no. 3, (1998).

[11] E. M. Diana and J. M. Webb, "Using Geographic Maps In Classroom: The Conjoint Influence of Individual Differences and Dual Coding on Learning Facts”, Learning and Individual Differences, vol. 9, (1997), pp. 195-214.

[12] T. Jones and C. Berger, "Students' Use of Multimedia Science Instruction: Designing for the MTV Generation?", Journal of Education Multimedia and Hypermedia, vol. 4, no. 4, (1995), pp. 305-320.

[13] A. Neville, "Native American Students' Self-perception Regarding Gardner's MI", University of South Dakota, (2000).

[14] J. R. Anderson, “Cognitive Psychology and its Implications”, New York: Freeman, (1995).

[15] D. P. Kauchak and P. D. Eggen, "Learning and Teaching: Research-based Methods", US, Boston: Pearson Educ., Inc., (2003).

[16] T. G. Morrison, J. S. Jacobs and W. R. Swinyard, "Do Teachers Who Read Personally Use Recommended Literary Practices in their Classrooms? Reading Research and Instruction", Brigham Young University, (1999), pp. 38-100.

[17] H. F. Silver, R. W. Strong and M. J. Perine, "So Each May Learn", New Jersey: Silver Strong \& Associates, (2000).

[18] D. Goleman, “Emotional Intelligence”, New York: Bantam Books, (1996).

\section{Author}

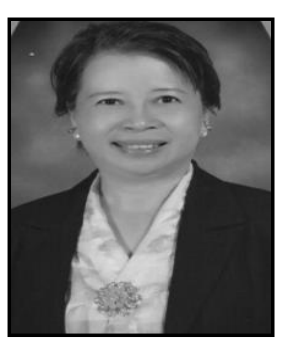

Dr. Maria Lilibeth G. Castil

1987 AB in Psychology, Mindanao State Univ., Marawi City, Phil. 1997 MA in I/O Psychology, San Carlos Univ., Cebu City, Phil. $2005 \mathrm{PhD}$ in Educ. Management, Holy Name Univ., Tagb. City. Phil.

1987 1989 Guidance Counselor/SST, BNCHS, Agusan del Sur, Phil.

1989 1992 Guidance Coordinator, Central Mindanao Univ., Bukidnon

$1992 \sim$ Bohol Island State Univ. (BISU), Tagbilaran City, Professor 2006 2010 BISU Asst. Dean, College Dean of Education 2010 BISU Director for Instruction 2010 AACCUP Accreditor

Published papers on areas related to the teaching-learning process, milieu and factors affecting learning in Refereed Journals of Philippine Association of Institutions for Research; Research and Development Training Institute; Kaplag, the BISU Journal. 
International Journal of Education and Learning Vol.5, No.2 (2016) 